\title{
Las fronteras del Estado: región, gobierno y luchas sociales en Quito (1992-2010)
}

\author{
State's limits: region, government and social struggles \\ in Quito (1991-2010)
}

Víctor Hugo Torres D. ${ }^{1}$

vtorres@ups.edu.ec

\section{Introducción}

La ciudad de Quito vive una tensión indivisible en su estructura espacial, pues al tiempo que es la capital del país, también es la sede del Gobierno, y el referente de la centralidad del Estado-nación. Las pugnas por la capitalidad y la centralidad están presentes en la historia reciente de la sociedad quiteña, marcando la manera cómo las elites locales se relacionan con el Estado, el sentido que va adquiriendo la gestión del gobierno municipal y los imaginarios urbanos que confieren identidad a sus habitantes. No se trata de una convencionalidad derivada de la división político-administrativa, montada con el avance del Estado que estableció un entramado administrativo por niveles; sino que la tirantez de intereses entre capitalidad y centralidad expresa, ante todo, en mi opinión, la modalidad de articulación territorial, económica y de poder de la región quiteña con el Estado ecuatoriano, la misma que se "renovó" en las dos últimas décadas del siglo veinte con la asunción del estatus de distrito metropolitano.

La problemática de estudio se fundamenta en la incertidumbre de que la declaración de la ciudad de Quito como distrito metropolitano en el año 1992, y su implementación a lo largo de las décadas de los noventa y dos mil, más allá de que amplió la autonomía municipal para la gestión local de bienes, servicios, infraestructura y beneficios urbanos de una ciudad en expansión, también expresa la readecuación hegemónica de los intereses particulares sobre el interés público, pues las políticas urbanas se harán, de modo predominante, bajo modalidades empresariales y de mercado en concordancia con el proceso territorial

1 Doctor (c) en Ciencias Sociales. Director de Investigaciones en la Universidad Politécnica Salesiana. 
de vinculación de la economía regional al mercado internacional, creando una impronta espacial, un estilo de gobierno de la ciudad e imaginarios urbanos que reforzaron la capitalidad quiteña a costa de la centralidad del Estado-nación.

En la capital del país, durante las dos últimas décadas del siglo XX se dio un suigéneris proceso de acoplamiento local-nacional, por el que mientras la capitalidad de la ciudad se fortalecía con la configuración territorial metropolitana para la vinculación al mercado internacional, la centralidad estatal se fragmentaba con las disputas regionales y la presión local por la autonomía. Indicativo de ello fue la notoria estabilidad de los alcaldes y autoridades locales en la capital del país, contrastada, simultáneamente, con la crisis de gobernabilidad y la recurrente sucesión presidencial; pues al tiempo que en el municipio de Quito se eligieron cuatro alcaldes, cruzando la plaza de la Independencia, al frente, en el palacio de Carondelet, se eligieron ocho presidentes en el mismo período. Disimilitud que reforzó la creencia liberal de que en lo local sí funciona aquello que en lo central no funciona.

¿Cuál es el sentido público de la modernidad urbana que empezó a configurarse en la ciudad con la asunción de la condición de distrito metropolitano? ¿Cómo contribuye la transformación territorial del distrito metropolitano a una nueva fase de vinculación de la economía regional al mercado mundial? ¿Hasta dónde el consecuente formato empresarial y corporativo adoptado por el municipio capitalino, soluciona los problemas estructurales de la ciudad o los subordina a los intereses económicos regionales? ¿De qué manera los imaginarios metropolitanos cimentan prácticas culturales de la población quiteña polarizada entre valores individuales de progreso y valores comunitarios de atraso? Y en último lugar, ¿Las luchas sociales urbanas tienden a inclinarse hacia la defensa de la capitalidad de la ciudad, en detrimento de la centralidad del Estado?

Buscando posibles respuestas formulo la siguiente hipótesis: las tensiones entre capitalidad y centralidad en Quito expresan la heterónoma articulación de las elites regionales en el Estado-nación, y dicen, al mismo tiempo, del débil y conflictivo acoplamiento entre lo local y lo nacional. La declaración de Distrito Metropolitano de Quito actualizó el proceso de incorporación efectiva de la economía regional al sistema económico mundial, acentuándose, en contrapartida, la segregación urbana y la inequidad territorial, pues en las dos décadas el hábitat quiteño pasó de ser el ámbito predominante de la "reproducción social" 
que, de alguna forma, se preocupaba de la provisión del bienestar de sus habitantes, a convertirse en el territorio de organización de la "producción social" enfocado, más bien, en la provisión de entornos favorables para los negocios y servicios urbanos. La gobernanza local devino confusa, pues la tensión entre capitalidad y centralidad, al igual que las luchas sociales, ocurrieron en el "inter-fase" del Estado-nación y la ciudad región.

No obstante que en el país, desde mediados de la década de los 90, se vivieron recurrentes eventos de inestabilidad política, en Quito, en cambio, no se dio un desplazamiento sustantivo de la conflictividad político-social desde lo nacional a lo local, o del Gobierno central al gobierno territorial como ocurrió en otros países de la región, sino que la ciudad experimentó, paradójicamente, un abigarramiento de sucesos económicos, políticos y culturales entrecruzados. Al tiempo que las elites quiteñas consolidaban los negocios inmobiliarios, bancarios y comerciales, el municipio moldeaba el distrito metropolitano bajo el influjo de adecuación competitiva a la globalización, y en la ciudad se intersectaban las luchas por la capitalidad, la reproducción social y la convivencia.

De ahí que el propósito ecuménico de la investigación, por así decirlo, es comprender la modalidad contemporánea de articulación de la ciudad región quiteña al Estado-nación ecuatoriano, con la declaratoria de distrito metropolitano en las dos últimas décadas del siglo XX. Interesa analizar la dinámica de la economía regional con la creación de los enlaces internos que conectan la ciudad al mercado internacional, examinar la consecuente adopción del estilo empresarial en el municipio capitalino para la implementación de las políticas metropolitanas, interpretar los imaginarios urbanos modernos y neocoloniales que se configuran con la condición metropolitana, y explicar, a través de una taxonomía, las luchas sociales urbanas en el período.

\section{La región quiteña: enlaces económicos y flujos territoriales}

Cabe señalar que los distintos discursos académicos y políticos acerca de lo urbano, el territorio y el gobierno de la ciudad, al igual que los fundamentos conceptuales y metodológicos de los dispositivos de acción pública como son los planes, programas, políticas y proyectos municipales, incluso las prácticas 
culturales de los actores urbanos, en buena medida están influenciados, por no decir condicionados, por el peso de las ideas predominantes en una etapa. Es el caso de las dos últimas décadas del siglo XX que estuvieron marcadas por la hegemonía de las doctrinas liberales que inclinaron la frontera entre lo público y lo privado hacia el mercado y la competencia, y a explicación de lo urbano por la influencia de la globalización sobre las localidades, moldeando políticas, imaginarios y comportamientos colectivos.

El debate latinoamericano sobre la ciudad región se enfoca en la existencia de macro regiones urbanas como consecuencia de la transición de ciudades urbanísticamente centralizadas y relativamente delimitadas, hacia regiones urbanas disgregadas y de límites indeterminados (De Mattos, 2012: 95). En la explicación de esta transición predomina un enfoque economicista que ve a las regiones urbanas como la agregación territorial inmobiliaria o "conurbanización", provocada por los nuevos servicios demandados por la penetración y expansión de los circuitos globales (véase Silva y Castillo, 2007: 46); o la región metropolitana como la porción del territorio con vocación competitiva ante la globalización, debido a la capacidad de especialización con el desarrollo de enclaves productivos o clusters; los centros urbanos metropolitanos como polos de crecimiento económico e innovación, a consecuencia de las "economías de aglomeración" con capital social, físico y sociedades del conocimiento; o las áreas metropolitanas como localidades que operan en calidad de actores competitivos de los mercados internacionales, con reglas de relacionamiento propias y globales (véase Mancheno y Terán, 2012: 139-152).

Propongo analizar la ciudad-región en su vinculación al mercado internacional, pero condicionada por la modalidad histórica de articulación de las elites, el territorio y el gobierno local al Estado-nación, pues configurar la ciudad es, al mismo tiempo, construir el Estado. Para ensamblar esta perspectiva analítica centrada en los actores regionales, recurro a tres enfoques teóricos que comparten el análisis del sistema mundo y que estando alejados del estructuralismo economicista, orientan la comprensión dinámica, conflictiva diríase, del proceso contemporáneo de la ciudad región y son: la incorporación nominal o efectiva de la economía local al mercado mundial, el territorio como agregación de flujos de capital y relaciones políticas, y el gobierno metropolitano como 
estructura de relaciones de dominación y clases sociales en una relación heterárquica con el Estado-nación.

El enfoque de incorporación al mercado mundial desarrollado originalmente por Giovanni Arrighi y aplicado, en este caso, por Juan Maiguashca en su reinterpretación histórica del período cacaotero ecuatoriano, se refiere al carácter cambiante de la incorporación de una economía agroexportadora al sistema mundial, pues para Arrighi las modalidades de incorporación al mercado mundial pueden variar en direccionalidad e intensidad, pueden ir para adelante o para atrás, pueden articular una posición subordinada en la división internacional del trabajo o bien pueden dar lugar a un "crecimiento económico endógeno que se aprovecha del mercado mundial en lugar de ser su víctima", concluye Maiguashca al aplicar los conceptos de Arrighi al análisis del período cacaotero ecuatoriano (Maiguashca, 2012: 91).

Maiguashca sintetiza el enfoque de Arrighi señalando que el proceso histórico de incorporación de una economía local al mercado mundial, puede ser nominal o efectiva. Es nominal cuando la incorporación se realiza sin alterar la matriz productiva dominante en el territorio recién incorporado; por el contrario, la incorporación es efectiva cuando se cambia sustantivamente la matriz productiva local, pudiendo ser una incorporación efectiva y periférica cuando el entramado y conexiones de los "enlaces externos" con el centro capitalista son mayores al entramado y conexiones de los "enlaces internos" de la producción local. En cambio, si los "enlaces internos" predominan sobre los externos entonces se trata de una incorporación efectiva no periférica (Maiguashca, 2012: 68).

Comparto con Maiguashca que el enfoque de Arrighi de la inscripción variable al sistema mundial tiene tres razones de utilidad para la investigación de la economía regional. Primero, porque se trata de una "visión no lineal" del proceso histórico de incorporación al sistema mundial que experimenta avances y retrocesos, crítica, al mismo tiempo, de los enfoques que ven la inserción al sistema mundial como el paso de la tradición a la modernidad siguiendo el curso de los países más adelantados, a los cuales se los percibe como el modelo del progreso. Segundo, porque lejos de sujetar a los actores locales a las fuerzas estructurales, les confiere protagonismo en los procesos de incorporación de la economía regional al sistema mundo, evidenciando la pluralidad de intereses de 
los diversos estamentos movilizados, así como la heterogeneidad y diferencia cultural de la sociedad involucrada, sus expectativas y luchas sociales. Tercero, porque considera importante en los procesos de incorporación a la economía internacional, el estudio no solo de los aspectos económicos sino también de las estructuras sociales que los conforman, al igual que las acciones estatales que los posibilitan, pues lo que hace o deja de hacer el Estado en su dimensiones nacional o local, es decisivo para la incorporación de la economía regional al mercado mundial. Se trata de una perspectiva integral de análisis que combina el examen del dato económico, junto con la reflexión sobre la composición de clase y el papel del Estado (Maiguashca, 2012: 69-71).

El enfoque de Arrighi, propongo, también es pertinente para comprender la dinámica contemporánea de incorporación de la economía quiteña al mercado mundial, la que hasta entrados los años ochenta era una economía predominantemente rentista basada en la modernización hacendaria del entorno urbano, en los negocios inmobiliarios, el comercio importador y una tenue industrialización; la misma que pasó, con la asunción del distrito metropolitano en las décadas de los 90 y 2000, a otra modalidad de mayor intensidad en la incorporación al mercado mundial.

Se reorganizó la economía regional con la inusitada expansión urbana que concentró monopólicamente los negocios inmobiliarios, la renta del suelo y el crédito bancario. El centro histórico de la ciudad asumió la condición de patrimonio cultural de la humanidad, con la consecuente inversión pública y privada para revalorizar el patrimonio edificado; mientras se reestructuró la agroexportación florícola, en menor escala hortícola, del mismo entorno rural; se amplió sustantivamente el comercio importador de bienes de consumo; se concentró el acceso de alimentos combinando la producción-comercialización local con la importación; y se profundizó la dependencia pública de la renta petrolera. Usando las categorías de Arrighi, puede decirse que la ciudad-región quiteña pasó de una incorporación "nominal" a una sui géneris modalidad de incorporación "efectiva y periférica" al mercado mundial, en la que predominan la debilidad de los enlaces internos que son marcadamente terciarios y de servicios.

Planteo explorar cómo el alcance de los "enlaces internos" de la ciudad de Quito con el resto del país, se modificó sustantivamente en este último período, readecuándose los factores productivos como la concentración en el acceso y 
control de la tierra urbana y rural, la universalización de la organización empresarial privada y pública, la condensación del capital financiero y comercial, y la sobre explotación de la fuerza de trabajo que, en conjunto, esparcieron por el territorio del norte del país una economía de servicios; expandiéndose, en contrapeso, un vasto y variado campo de producción y comercialización popular que también forma parte de los enlaces internos de la economía regional.

Por otro lado, retomo el enfoque del territorio como una agregación de flujos de capital y relaciones de poder formulado por David Harvey. Se trata de una perspectiva teórica que considera al territorio como una creación social, en la que el denominado "entorno natural" está sometido a las transformaciones provocadas por la actividad humana que remodela lo que el autor denomina como una "segunda naturaleza" (Harvey, 2010: 155). Si bien son numerosos los agentes que intervienen en la remodelación geográfica de la naturaleza, en la actualidad, dice Harvey, el capital y el Estado son los principales agentes sistémicos que intervienen en el paisaje de la acumulación que evoluciona constantemente, estimulado principalmente por las necesidades especulativas de nueva acumulación y solo secundariamente atendiendo a las necesidades de la gente (Harvey, 2010: 156).

El territorio de la ciudad región puede considerarse como una configuración espacio-temporal levantada en torno a la acumulación de capital, que forma parte del avance del Estado-nación y delimita la base territorial del poder político. Las ciudades, nos recuerda Harvey, se trazan en medio de la tensión entre el otium o "disfrute" y el negotium o "beneficio", su inclinación hacia uno u otro sentido depende de las luchas sociales y de clase en la formación del hábitat humano donde se establecen las relaciones afectivas, la solidaridad social, las subjetividades políticas y los significados simbólicos (Harvey, 2010: 162).

La aseveración de que, históricamente, son diversas las formas de agrupación socio-cultural asentadas en el territorio que antecedieron al ascenso del capitalismo, y de que las modernas instituciones jerárquicas son las que efectivamente traman continuamente el territorio y el hábitat para organizar a las poblaciones y afianzar las relaciones de poder, con lo que el territorio se explica por el peso de las instituciones modernas, se aplica plenamente para el caso de la ciudad región quiteña. 
Aunque la ciudad y el municipio -como dispositivos públicos de distribución y administración espacial- eran ajenos al hábitat de los pueblos originarios del territorio que actualmente es el Distrito Metropolitano de Quito, durante los períodos colonial y republicano fueron paulatinamente conformándose y enraizándose en la geografía regional como las instituciones económicas, políticas y administrativas que urdieron la nueva configuración espacio-temporal, de naturaleza urbana y centralista, que acabaron encajando y sometiendo al territorio. La ciudad se mantuvo encapsulada como una pequeña urbe conventual hasta entrado el siglo XX, el mismo que atestiguó un crecimiento urbano sostenido en las primeras cuatro décadas, luego desde los años 70 en adelante, un acelerado fenómeno de expansión urbana que septuplicó su tamaño inicial. Puede decirse que los últimos veinte años con la adopción del distrito metropolitano, representan la consolidación espacial de un largo y discontinuo proceso histórico de conformación urbano-regional que va de la mano del afianzamiento del gobierno municipal quiteño.

De ahí que las configuraciones regionales internas del país respecto de la división internacional del trabajo y los sistemas de producción, obedecen, esencialmente, a la conjunción de fuerzas económicas y políticas, antes que a las denominadas ventajas naturales o comparativas. Suponen la articulación local de organizaciones y tecnologías, de relaciones sociales y con la naturaleza, de sistemas de producción, modos de vida y cosmovisiones culturales que se sellan con dispositivos territoriales institucionales y administrativos específicos, siempre bajo la tutela del Estado que opera como el "contenedor geográfico insustituible".

El éxito de un Estado local está en proporción a su capacidad para captar flujos de capital, generar condiciones favorables para una nueva acumulación de capital dentro de su circunscripción, y mejorar la calidad de vida de sus habitantes (Harvey, 2010: 166). Puede decirse que el municipio de la ciudad región, se encuentra inmerso en una continua emulación con otros gobiernos locales de similar condición, por atesorar mayor capital e inversión dentro de sus fronteras, volviéndose la acumulación en el objetivo estratégico de la gobernabilidad local.

Según el autor, el capitalismo requiere por igual de territorios e individuos libres que se dediquen a la especulación y a la innovación empresarial, porque 
"dinamizan al capitalismo y mantienen en movimiento la acumulación de capital”, por lo que el principal enigma de la organización política son las tensiones del Estado soberano con otros poderes e individuos, no solo capitalistas, sino de la propia ciudadanía en su diversidad y heterogeneidad, tensiones que siempre "han sido inestables, contingentes e intensamente problemáticas" (Harvey, 2010: 166). Los sistemas políticos no solo obedecen a la acumulación de capital, sino que la voluntad del pueblo también juega un papel propio y decisivo, por lo que la idea generalmente asumida de que el capitalismo, el progreso o la modernidad promueven la homogeneidad geográfica, es errada; por el contrario, fomentan la heterogeneidad y la diferencia, pues las inequidades territoriales son consustanciales a la acumulación de capital, y devienen fundamentales para su reproducción, aunque los dispositivos institucionales y administrativos también están sujetos a los efectos de la disputa política (Harvey, 2010: 170).

El capitalismo implica un denso entramado de vínculos $-\mathrm{o}$ enlaces en el sentido de Arrighi- entre el Estado, las finanzas y las corporaciones que propaga la competencia en todo el sistema estatal y social, mientras las formas territoriales de organización prosperan con relativa autonomía, pero insertas también en el proceso competitivo de acumulación. El sentido de los enlaces permite diferenciar entre la lógica de poder con exigencias territoriales e intereses políticos propios de la voluntad popular, y la lógica capitalista del poder ${ }^{2}$ vinculada al acaparamiento de "dinero en manos privadas y empresariales", con el propósito de acumular sin fin los beneficios. No obstante, hay un punto de intersección entre ambas lógicas para fines del nexo Estado-finanzas, aunque sus actores y motivaciones sean distintas y estén, inextricablemente, entretejidas, puesto que el dinero es ante todo una forma clave de poder social que tanto el Estado como los capitalistas ansían.

Para Harvey, el control social del espacio es la forma principal de poder social que puede ejercer un grupo o clase social sobre otro, también en forma imperialista como "poder de un pueblo sobre otro", siendo a la vez un poder ex-

2 En este estudio se asume la definición de poder planteada por Charles Tilly (1992), esto es: el proceso histórico de interacción entre capital y coerción (léase dominación) que construye Estados y ciudades, entendiéndose como coerción a toda "aplicación concertada, como amenaza o como realidad, de acciones que por lo general causan pérdida o perjuicio de personas, o a las posesiones de particulares o de grupos, los cuales son conscientes tanto de la acción como de sus posibles daños" (Tilly, 1992: 44). 
pansivo que posibilita innovar y crear, o un poder represivo para obstaculizar, paralizar y de ser el caso devastar. La simple ocupación del poder estatal no semeja una genuina transformación anti sistémica, pues solo cuando los distintos ámbitos de actividad dentro del sistema de evolución conjunta se colocan en el mismo sentido, es posible que sea una transformación revolucionaria a gran escala que se distancie del dominio capitalista, lo cual no significa desvalorizar el poder del Estado y trasladar, exclusivamente, el sentido del cambio a la sociedad civil y la vida cotidiana. El asunto no es si el Estado es la forma válida de organización social de los asuntos humanos, sino qué tipo de disposición territorial del poder podría ser la más apropiada para "iniciar la transición a algún otro modo de producción”, sentencia Harvey (2010: 173).

Provisto de estos asertos, planteo que en el territorio del actual distrito metropolitano se protagoniza la más reciente disputa espacial de la economía y el poder regional quiteño, por la que se controla y administra la población, el trabajo, el suelo y los recursos públicos para fines de la acumulación de riqueza y la persistencia del poder de las minorías, recreando una geografía que "naturaliza" los negocios y emprendimientos privados como condición de bienestar y progreso, sobreponiendo las políticas productivas a las políticas de reproducción social. Allí se estimulan los flujos económicos y de poder que urden los enlaces internos-externos para la incorporación regional al mercado mundial, que aunque se pretenden inclusivos y prósperos para los habitantes del distrito metropolitano, son en realidad parte del crecimiento urbano concentrador y desigual que ahonda las inequidades espaciales y sociales, al tiempo que universaliza la modernidad urbana como imaginario de vida, en medio de una deleznable gobernabilidad local.

\section{Poder y heterarquía regional}

La dinámica del Distrito Metropolitano de Quito durante los años 90 y 2000, considero que no es un caso más de la práctica generalizada durante el período de resurgimiento liberal, de desplazamiento del conflicto social desde el ámbito del Estado-nación y el lugar del trabajo, al territorio, a la localidad. Aunque, en efecto, sí se mitificó el nexo entre lo local y lo global (Borja y Cas- 
tells, 2001), se trata de un espejismo neoliberal de que a la ciudad contemporánea le corresponde, llanamente, integrarse a la globalización, la que es asumida como su derrotero y oportunidad. En esta visión, al gobierno metropolitano le compete crear las condiciones que le permitan a la ciudad capital ocupar una posición competitiva, asumiendo funciones nodales respecto de otras ciudades igualmente metropolitanas.

El espejismo de que se puede entrar en una cabal mercantilización de la ciudad región, forma parte de la creciente creencia en los beneficios que se desprenden de la globalización del libre mercado, aunque quienes aprecian con mayor ímpetu el impacto de esta globalización son en realidad los que menos se benefician de ella, polarizándose, como contrapartida, las visiones entre aquellos que se encuentran al abrigo de sus efectos negativos, de quienes carecen de amparo. Para aquellos que viven fundamentalmente de su trabajo, la globalización del libre mercado trae aparejado un "caris siniestro", porque en la práctica socaba la capacidad del Estado y sus sistemas de bienestar, advierte el historiador británico Eric Hobsbawm (2007: 10).

La trayectoria hacia una región competitiva está minada por los efectos perversos de un urbanismo sometido a la globalización del libre mercado, que no solo atenta contra la cohesión social porque acentúa la marginalización de la población, sino que bloquea las posibilidades del desarrollo endógeno regional. La consecuente conflictividad social marca el derrotero regional, por lo que el resurgimiento del discurso de la ciudad con la recuperación del espacio, la apropiación colectiva de barrios, edificaciones, plazas y calles son expresiones de resistencia a la globalización del libre mercado y de reinvención de lo público.

En el medio de la tensión entre la globalización como oportunidad para la ciudad y la resistencia a la globalización con la recuperación local de la esfera pública, se halla el gobierno de la ciudad, el municipio metropolitano, cuyas principales políticas son impulsadas por los requerimientos productivistas de la idealizada competitividad territorial, aunque en la práctica no se disponga de las capacidades, competencias y recursos públicos para ello, con lo que "la gobernabilidad de los territorios urbano-regionales se convierte en un difícil desafío", señala Jordi Borja (2011: 22). 
Según Manuel Castells, el municipio es la institución de gobierno correspondiente al ámbito territorial subnacional, su dinámica y rol están determinados, fundamentalmente, por los rasgos económicos, políticos y culturales del territorio que administra y del Estado-nación del que forma parte. Estando conectado con el entramado de relaciones sociales de producción y distribución, el municipio conforma una estructura de poder local que está marcada por las relaciones generales de poder de la sociedad nacional; no es una réplica a escala local del poder central, tampoco el simple dispositivo gubernamental del caciquismo y clientelismo territorial, sino que revestido de estas características es un factor constitutivo del poder económico y político del país.

Por ello, los municipios, pese a que históricamente fueron la "trama institucional" sobre la que se constituyó el Estado-nación, contemporáneamente están insertos en una práctica pública inversa por la que es el nivel central del Estado, como expresión de las relaciones generales de poder de la sociedad, el que establece la división política administrativa del territorio de cada municipio, asignándole competencias exclusivas y concurrentes en el marco general del Estado y la sociedad. Los municipios tienen una autonomía relativa por su condición de gobiernos electos y por ser el nivel descentralizado del Estado, pero su sola agregación no es suficiente en la conformación del Estado-nación, se requiere, simultáneamente y en sentido bidireccional, mutual o heterónomo, tanto de la centralidad política y territorial como condición de la redistribución económica, cuanto de la descentralización municipal por su condición de mayor cercanía y compenetración con la sociedad. En este sentido, "las relaciones Estado central-municipio son el indicador más claro de las relaciones generales entre el Estado y la sociedad civil", anota Castells (1987: 300).

Me interesa destacar el concepto de "campo"3 de disputas o luchas políticas que encierra esta definición de municipio. Según Castells el municipio por ser el eslabón descentralizado del Estado, se convierte en un campo de lucha privi-

3 El concepto de "campo" originalmente planteado en la sociología por Pierre Bourdieu y emparentado con las teorías de sistemas y subsistemas, es retomado por el filósofo Enrique Dussel, que define el campo político como el ámbito posible de las acciones e instituciones políticas en las que el sujeto opera como actor de una función, como "participante de múltiples horizontes prácticos", porque está inmerso en redes intersubjetivas. El campo político deviene en un "ámbito" atravesado por fuerzas, sujetos con voluntad y poder, en espacio político de colaboración, coincidencias y conflictos (Dussel, 2006: 15-18). 
legiado entre las fuerzas dominantes en la sociedad y las fuerzas dominantes en el nivel central del Estado, en el que el sentido del poder depende de las fuerzas que tengan la hegemonía en la sociedad. El municipio expresa directamente las relaciones políticas dentro del Estado-nación, refleja una forma de la representación entre gobernantes y gobernados como consecuencia de las relaciones de poder en el conjunto de la sociedad: "la política municipal aparece por lo tanto como uno de los ejes principales de la dialéctica contradictoria entre representación popular y dominación de clase en el Estado democrático" (Castells, 1987: 301).

Sin duda que las relaciones entre clases sociales, elites y estamentos locales con el Estado son complejas, más aún en las sociedades periféricas del sistema mundo capitalista en las que la configuración de la hegemonía es posible únicamente con el control del Estado, cuestión que no se reduce solo al funcionamiento del aparato del Estado y a la disputa de los recursos públicos, sino también a la dinámica política de disposición del bloque dominante, a los mecanismos por los cuales se configuran las alianzas, compromisos y relaciones heterónomas entre las clases hegemónicas (véase Buci-Gluksman, 1978).

En este proceso, un factor clave es el carácter territorial de la hegemonía que diferencia, o asimila, a las elites y clases dominantes con los niveles administrativos del Estado y las regiones. El control del municipio de la ciudad-región, de acuerdo con el alcance de los enlaces internos de la economía regional, puede dar lugar a una relación jerárquica y subordinada a la centralidad, o a una relación heterónoma y constitutiva de la centralidad, a una forma de centralidad en sí misma en el territorio.

La región, como constitutiva de la centralidad, supone una comprensión de las relaciones territoriales más allá del concepto moderno de jerarquía, en la perspectiva de construir un nuevo lenguaje como lo proponen Santiago Castro-Gómez y Ramón Grosfoguel (2007), a propósito del "pensamiento heterárquico" planteado por el sociólogo griego Kyriakos Kontopoulos (1993). Los sistemas sociales territoriales no son cerrados, ni están sometidos a una lógica única que determina todo desde una sola jerarquía de poder, contrariamente, obedecen a sistemas de poder tramados con dispositivos heterónomos que están enlazados en red. 
Las heterarquías, dicen los autores, son distribuciones complicadas de poder en las que no existe un solo y exclusivo nivel básico que gobierna sobre los demás, sino que todos los niveles despliegan grados de autoridad en diferentes aspectos particulares y según momentos históricos concretos. En un entramado heterárquico la combinación de los elementos disfuncionales al sistema no estará insuficientemente acabada, como en la jerarquía, sino que será siempre parcial; lo cual significa que en el capitalismo global no hay lógicas completamente autónomas ni tampoco una sola lógica determinante que gobierna sobre todas las demás, contrariamente, existen procesos complejos, heterogéneos y múltiples, con diferentes temporalidades, dentro de un solo sistema-mundo de larga duración (Castro-Gómez y Grosfoguel, 2007: 18).

De acuerdo con Kontopoulos una estrategia epistémica para la comprensión jerárquica de la estructura social, supone articular la multidireccionalidad propia de los sistemas sociales en dos aspectos: de una parte, los "subsistemas de complejidad creciente" derivados de las decisiones gestadas en los "subsistemas micro" que acotan a los subsistemas inferiores y a las microdecisiones, y que modifican todo el sistema; y de otra parte, la concordancia recíproca de las variadas micro estructuras que se ensamblan para producir "subsistemas de complejidad creciente", cuestión que es propia a la naturaleza multiestructural de los sistemas sociales. Con lo que el concepto de jerarquía va más allá de la determinación completa de los subsistemas macro sobre los subsistemas micro, dando lugar a una estrategia epistémica de "trascendencia sistémica" $\mathrm{u}$ holismo (Morales, 2007: 5).

En cambio, la heterarquía se propone como una estrategia epistémica de "emergencia moderada", definida como "la subdeterminación de la(s) macroestructura(s) por las micropartes dadas y como la emergencia semi-autónoma de fenómenos de nivel superior fuera de los de nivel inferior" (Kontopoulos, 1993: 12). En las heterarquías, dice el autor, no hay un único subsistema gobernante, ya que cada subsistema despliega su particular influencia sobre los demás, por lo que se muestran también como sistemas "débilmente acoplados" a consecuencia de una interacción descentralizada, incitada por los disímiles y encontrados intereses particulares. Tampoco se da la inclusión completa o casi completa de un subsistema respecto de otro, pues las heterarquías se caracterizan por tener múltiples accesos, vínculos y determinaciones entre los distintos sub- 
sistemas; "de ahí que una teoría que se refiere a situaciones sociales incompletamente ordenadas, con niveles semi-independientes uno del otro y entremezclados en formas desiguales, es una teoría heterárquica", dice Kontopoulos (1993: 226).

Mientras en las jerarquías los subsistemas superiores se erigen con la imposición de restricciones a los subsistemas inferiores, en las heterarquías no existe una jerarquía claramente definida entre subsistemas, por el contrario, coexisten entrecruzamientos de niveles y restricciones superiores e inferiores, al igual que mutuas determinaciones entre macro y micro sistemas que dificultan identificar el nivel, causalmente, más importante del conjunto del sistema social (Kontopoulos, 1993: 66).

En esta perspectiva, el poder y la hegemonía en la ciudad región quiteña puede verse como un entramado de relaciones heterónomas respecto del Gobierno central, como un estructura equivalente de relaciones de poder, en el mismo nivel aunque insuficientemente acopladas, no solo porque es parte del proceso territorial de conformación del bloque de clases hegemónico, sino porque la propia capital del país es constitutiva de la estructura centralizada del Estado-nación ecuatoriano. El gobierno metropolitano tiende a ser algo más que un nivel municipal, aunque forme parte de la división política administrativa subnacional, puesto que experimenta el entrecruzamiento de niveles y restricciones, así como el solapamiento de los subsistemas nacional y regionales, los mismos que se intersectan e influyen entre sí sin determinarse completamente y dando lugar, más bien, a una disímil articulación en el Estado-nación.

La política municipal no es únicamente la administración de los objetos, de los bienes y servicios públicos, sino también el gobierno de las personas, de las relaciones entre las elites, clases y estamentos sociales; es el régimen que enlaza a los habitantes de la urbe en su diferencia y diversidad con las autoridades locales. Sus consecuencias en la cotidianeidad de la ciudad y la región pueden ser de regulación o exacerbación de las dinámicas espaciales, también pueden ser de mediación, negociación o facilitación de las demandas por la conservación del orden, o de las presiones colectivas por el cambio social. En cualquier caso, se trata siempre de luchas y disputas por los recursos y las subjetividades públicas que se dan en el escenario político municipal, el mismo que forma parte de las intersecciones regionales y nacionales por la hegemonía del Estado-nación. 


\section{Perspectiva analítica}

En suma, en la ciudad-región quiteña examino la creación de "lazos internos", destacando la tendencia de concentración empresarial en detrimento de la economía popular, en medio de una urbanización signada por la irracionalidad y el mercado que tiene como trasfondo la consolidación de una estructura espacial de poder proclive a la reinserción de la economía regional al mercado mundial. Explico el gobierno del distrito metropolitano como una estructura municipal heterárquica, que se recrea a sí misma en un híbrido de Estado-empresa y prioriza las capacidades institucionales afines a los flujos de capital, incluso en la prestación de los servicios urbanos para los habitantes de la urbe. Reseño los dispositivos de poder entre patricios y plebeyos en la gestión del municipio quiteño, el sentido de la modernización municipal que ensambla secretarías, administraciones zonales, empresas municipales de servicios y corporaciones, y la intersección de niveles y restricciones que configuran el sentido de la autonomía metropolitana.

Los imaginarios urbanos también son relevantes en la comprensión de la dinámica regional, en tanto muestran tensiones entre los actores sociales respecto de la ciudad, y la imbricación de socializaciones de sentidos individuales, comunitarios, colectivos y públicos en torno a la modernidad liberal que envuelve a la urbe, pues la memoria hace parte de encontrados procesos de reproducción social y producción de mercado, frente a la convivencia y gestión urbana. Subrayo el imaginario público municipal de la ciudad región que refuerza desde una postura monocultural mestiza la centralidad y capitalidad quiteña; el imaginario de las elites capitalinas que ve a la ciudad como una oportunidad de mercado y negocio, o el beneficio económico como condición del disfrute; y las otras visiones de la ciudad que, desde la diferencia cultural y lo subalterno, trazan heterogéneos sentidos que podrían devenir en una descolonización del imaginario quiteño.

Finalmente, narro las principales dinámicas de la acción colectiva en la ciudad, como campo de disputas por el control del espacio y locus de prácticas de poder social. Propongo una taxonomía social que diferencia entre tres tipos de luchas urbanas: 1) las luchas encabezadas por las elites quiteñas que ratifican la centralidad y la capitalidad, arrastrando tras de sí a amplios sectores 
medios y populares, incluso en ciertas coyunturas al movimiento indígena, y expresadas en las movilizaciones ciudadanas que provocaron las caías de los presidentes Abdalá Bucaram, Jamil Mahuad y Lucio Gutiérrez; 2) las luchas por la reproducción social en los llamados barrios marginales, como expresión de un vacilante movimiento popular urbano que levantó procesos de organización colectiva, pero que fue eclipsado por las maquinarias clientelares locales y 3) las nuevas luchas sociales por el derecho a la ciudad expresadas en plurales movimientos culturales, artísticos, de jóvenes, mujeres, ciclistas y peatones que demandan espacios de participación ciudadana y convivencia ante la inseguridad, contaminación, movilidad, violencia o contra el racismo y la discriminación, apostando por nuevos usos colectivos de los espacios públicos.

\section{Bibliografía}

Arrighi, G.

1979 "Pheripherization of Southern Africa, I: Changes in Production Processes". En: Review 3/2. 우 3. Vol. 2.

Borja, J.

2011 Revolución urbana y derecho a la ciudad. Quito: OLACHI-Municipio Metropolitano de Quito.

Borja, J. y Castells, M.

2001 Local y global La gestión de las ciudades en la era de la información. Barcelona: Taurus.

Brenner, N.

2013 "Tesis sobre la urbanización planetaria". En: Nueva Sociedad. № 243. Friedrich Ebert Stiftung, Argentina.

Buci-Gluksman, Ch.

1978 Gramsci y el Estado. Madrid: Siglo XXI.

Castells, M.

1987 Crisis urbana y cambio social. México: Siglo XXI.

Castro-Gómez, S. y Grosfoguel R. (comp)

2007 El giro decolonial: reflexiones para una diversidad epistémica más allá del capitalismo global. Universidad Central, Instituto de Estudios Sociales Con- 
temporáneos y Pontificia Universidad Javeriana, Instituto Pensar. Bogotá: Siglo del Hombre.

De Mattos, C.

2012 "Reestructuración económica y metamorfosis urbana en América Latina: de la ciudad a la región urbana". En: Questiones urbano regionales. Vol. 1. N ${ }^{\circ}$ 1. Revista del Instituto de la Ciudad, Quito.

Duhau, E.

2013 "La división social del espacio metropolitano: una propuesta de análisis". En: Nueva Sociedad. № 243. Friedrich Ebert Stiftung, Argentina.

Dussel, E.

200620 tesis de política. México: CREFAL-Siglo XXI.

Harvey, D.

2010 El enigma del capital y la crisis del capitalismo. Madrid: Akal.

Hobsbawm, E.

2007 Guerra y paz en el siglo XXI. Barcelona: Memoria Crítica.

Kontopoulos, $\mathrm{K}$.

1993 The Logics of Social Structures. Cambridge: Cambridge University Press.

Maiguashca, J.

2012 "La incorporación del cacao ecuatoriano al mercado mundial entre 1840 y 1925, según los informes consulares”. En: Procesos. №35. Semestre 1. Revista Ecuatoriana de Historia, Quito.

Mancheno, D. y Terán, J. F.

2012 "La ciudad-región en América Latina: un concepto entre el neoliberalismo y el posliberalismo". En: Questiones urbano regionales. Vol. 1. №1. Revista del Instituto de la Ciudad, Quito.

Morales, B. F.

2007 "Los conceptos de jerarquía y heterarquía en el análisis del desarrollo local". México: PROIMMSE-IIA-UNAM.

Silva, A. B. y Castillo

2007 "Dinámica metropolitanas en la era de la globalización: la promoción inmobiliaria para empresas en la ciudad de Sao Paulo". En: Eure. № 98.

Tilly, Ch.

1992 Coerción, capital y los Estados europeos 990-1990. Madrid: Alianza. 